\title{
shotgun encodes Drosophila E-cadherin and is preferentially required during cell rearrangement in the neurectoderm and other morphogenetically active epithelia
}

\author{
Ulrich Tepass, ${ }^{1,3,4}$ Eileen Gruszynski-DeFeo, ${ }^{1,4}$ Thomas A. Haag, ${ }^{1}$ Lili Omatyar, ${ }^{1}$ Tibor Török, $^{2}$ \\ and Volker Hartenstein ${ }^{1}$ \\ ${ }^{1}$ Department of Molecular Cellular Developmental Biology, University of California at Los Angeles, Los Angeles, California \\ 90024-1606 USA; ${ }^{2}$ Institute of Genetics, Biological Research Center of the Hungarian Academy of Sciences, Szeged, Hungary
}

\begin{abstract}
Adhesion molecules of the cadherin superfamily have an important role during vertebrate development. The $D E$-cadherin homolog $D E$-cadherin is the first classic cadherin isolated from invertebrates. We report here that DE-cadherin is encoded by the shotgun (shg) gene. shg is expressed in most embryonic epithelia and decreases in cells that undergo epithelial-mesenchymal transitions like the mesoderm or neural precursors. Removal of both maternal and zygotic shg function leads to severe defects in all epithelia expressing shg, suggesting that $D E$-cadherin, similar to vertebrate classic cadherins, has a crucial role for the formation and/or maintenance of epithelial tissues. Interestingly, the analysis of different shg alleles indicates that the requirement for shg in a given epithelium depends on the degree of its morphogenetic activity. Only epithelia involved in extensive morphogenetic movements require zygotic shg function in addition to maternal expression. In support of this view we find that suppression of morphogenetic movements rescues the zygotic shg phenotype. We find that in zygotic shg nulls the level of Da-catenin and Armadillo at adherens junctions is dramatically reduced, surprisingly also in epithelia that differentiate normally and possess a zonula adherens.
\end{abstract}

[Key words: DE-cadherin; epithelium; neurectoderm; morphogenesis; cell rearrangement]

Received November 29, 1995; revised version accepted January 31, 1996.

Morphogenesis describes the developmental process in which, by means of cell proliferation, cell movements, and reorganization of cell shape, simple and homogenous tissues turn into complex and diverse organs. On the molecular level, adhesion molecules, particularly a family of molecules called cadherins, have an important role to orchestrate morphogenetic movements during embryonic development (Takeichi 1991, 1995; Geiger and Ayalon 1992; Grunwald 1993; Kemler 1993; Ranscht 1994). Cadherins form a large family of membrane proteins defined by a particular structural motif, the cadherin domain, which mediates $\mathrm{Ca}^{2+}$-dependent homophilic adhesion. The so-called classic cadherins, among them $\mathrm{N}$-cadherin and E-cadherin, also possess a highly conserved cytoplasmic domain that binds to cytoplasmic

\footnotetext{
${ }^{3}$ Present address: Department of Zoology, University of Toronto, Toronto, Ontario, Canada MS51A1.

${ }^{4}$ These authors contributed equally to this work.
}

proteins called $\alpha$ - and $\beta$-catenin, thereby forming the cadherin-catenin complex. Catenins bind to actin filaments forming a link between membrane and cytoskeleton that is crucial for the function of the cadherins. The importance of cadherins for embryonic development has been demonstrated in numerous vertebrate systems. However, much remains to be learned about the role of cadherins during the control of specific morphogenetic movements. We report here the genetic characterization of the Drosophila gene shotgun (shg; Nüsslein-Volhard et al. 1984), that encodes the first classic cadherin $D E$ cadherin (Drosophila E-cadherin; Oda et al. 1994) isolated from invertebrates.

During vertebrate development, cadherins are expressed in a dynamic pattern. Expression domains of different cadherins are partially overlapping so that individual tissues express either a particular cadherin or a combination of cadherins. Experimental studies have shown that cadherins can control cell shape and movement in 
different ways. (1) Cadherins are responsible for stabilizing embryonic epithelia. Injection of a truncated dominant-negative form of E-cadherin causes lesions in the ectodermal epithelium in that it is normally expressed (Levine et al. 1994). A similar effect is observed in both epidermal ectoderm and neural tube after injection of a truncated form of $\mathrm{N}$-cadherin (Kintner 1992). (2) Cadherins control some aspects of epithelial cell shape. The cadherin-catenin complex is concentrated at the zonula adherens (ZA) (for review, see Kemler 1993), a cellular junction located at the apicolateral boundary of an epithelial cell. It has been demonstrated that E-cadherin recruits other transmembrane and cytoskeletal proteins to the region of cell-cell contact and thereby has an important role in the assembly of the lateral membrane domain (McNeill et al. 1990). The overexpression of the complete $\mathrm{N}$-cadherin molecule causes dramatic changes on epithelial cell shape during early Xenopus development (Detrick et al. 1990; Fuijimori et al. 1990). Cells of the epidermal ectoderm become cuboidal or columnar instead of being squamous. Cells of the neural tube lose their epithelial morphology and form irregular clusters. (3) Cadherins might be important for setting up boundaries between different epithelial compartments by preventing the mixing of cell populations with different fates. In vitro studies have demonstrated homotypic sorting of formerly nonadhesive culture cells that were transfected with different cadherin isoforms (for review, see Takeichi 1991). For instance, the differential expression of E-cadherin in the non-neural ectoderm, and $\mathrm{N}$-cadherin in the neural plate and neural tube epithelium is necessary for the segregation of these two tissues. This segregation process is blocked when both tissues express N-cadherin (Detrick et al. 1990; Fujimori et al. 1990). (4) Cadherins may control the orderly release of cells from an epithelium during epithelial-mesenchymal transitions. Epithelial-mesenchymal transitions represent a frequently encountered morphogenetic movement during embryogenesis. For example, while separating from the epithelial neural tube, the progenitors of the neural crest undergo an epithelial-mesenchymal transition and become migratory mesenchymal cells. Down-regulation of N-cadherin presumably has a pivotal role in the epithelial-mesenchymal transition of neural crest cells (Takeichi 1988). This function of cadherins also explains their properties as tumor suppressor genes. Thus, to become invasive, neoplastic cell lines typically undergo a radical structural reorganization from an epithelial to a mesenchymal morphology (Gabbert et al. 1985). In a variety of human carcinomas, down-regulation of E-cadherin and/or mutations in the E-cadherin gene are associated with the dissemination of neoplastic cells (for review, see Birchmeier 1995).

In recent years Drosophila has gained importance as a model system to study the formation of epithelia and movements in epithelial tissues. It could be shown that the Crumbs $(\mathrm{Crb})$ protein, a component of the apical membrane of all ectodermally derived epithelia, is a key regulator of apical polarity (Tepass et al. 1990; Wodarz et al. 1995). Crb is also essential for the formation of the ZA and hence determines the distribution of the cadherincatenin complex that is concentrated at the $\mathrm{ZA} / \mathrm{U}$. Tepass, unpubl.). Epithelium formation has been studied during cellularization of the blastoderm (e.g., Foe et al. 1993) and during the formation of the midgut epithelium (e.g., Tepass and Hartenstein 1994b). Movements in epithelial tissues have been analyzed during gastrulation (Costa et al. 1993) and imaginal disc eversion (Condic et al. 1991). In addition, two nonclassic members of the cadherin superfamily encoded by the genes fat and dachsous have been found in Drosophila that are involved in imaginal disc morphogenesis (Mahoney et al. 1991; Clark et al. 1995).

To further analyze the genetic and molecular mechanisms controling epithelial morphogenesis, we have screened existing collections of mutations for genes that are required for this process. Two markers were used, anti-Crb antibody to detect abnormalities in epithelial cell polarity, and MAb 22C10 to assay for defects in the pattern of sensory neurons. shg mutant embryos showed prominent defects when stained with either of these two markers. We therefore conducted a detailed analysis of the shg gene, that is presented in this paper. Our results show that shg encodes DE-cadherin, the Drosophila homolog of vertebrate E-cadherin (Oda et al. 1994). DEcadherin has been characterized as a $\mathrm{Ca}^{2+}$ dependent cell adhesion molecule that interacts with the Drosophila $\alpha$-catenin, $D \alpha$-catenin homolog (Oda et al. 1993, 1994), and Armadillo (Arm), that is closely related to vertebrate $\beta$-catenin (Peifer 1993, 1995).

Removal of both maternal and zygotic shg function leads to severe defects in all epithelia expressing the shg gene, suggesting that $D E$-cadherin, similar to vertebrate classic cadherins, has a crucial role for the formation and/or maintenance of epithelial tissues. Furthermore, we describe here the results of a genetic and developmental analysis of shg mutations and find that in epithelia that undergo large-scale movements that involve breaking and reforming of new adhesive contacts, as the ventral neurectoderm, zygotic shg expression is required. In contrast, morphogenetically less active epithelia like the dorsal epidermis do not depend on zygotic shg function, although they express shg at levels similar to the neurectoderm. These observations reveal a striking spatiotemporal correlation between the level of shg-DEcadherin required for maintaning epithelial integrity and the degree of morphgogenetic activity in a particular epithelial tissue. By suppressing individual morphogenetic movements and thereby rescuing the shg mutant phenotype we show directly that high levels of shg expression are required to maintain epithelial tissue structure during these morphogenetic movements.

\section{Results}

shg encodes $\mathrm{DE}$-cadherin

shg was cloned by using a P-element tag isolated from a collection of lethal P-element insertions on the second 
chromosome (Török et al. 1993). One line (P34-1) behaved as a shg allele in complementation tests and caused a weak mutant phenotype in homozygous embryos. This line was renamed shg $g^{P 34-1}$. The P-element insertion in the genome of $\mathrm{shg}^{P 34-1}$ is located at 57B13/ 14 , that is covered by the shg deletion Df(2R)D17 and therefore most likely represents the shg locus (Fig. IB). To demonstrate that the P-element insertion in shg ${ }^{P 34-1}$ is the cause for the shg mutation, a revertant analysis was conducted. Of 186 independent revertant lines, $45 \%$ were homozygous viable (wild-type revertants), whereas the remaining 103 lines were homozygous lethal and caused shg mutant phenotypes of various severity among them several alleles that caused a strong shg phenotype.

Genomic DNA adjacent to the insertion site in $s h g^{P 34-1}$ was cloned by plasmid rescue. The initial rescue fragment was extended to a small genomic walk, covering $\sim 20 \mathrm{~kb}$ (Fig. 1A). A sequence of genomic DNA flanking the P-element insertion site was found to be identical to part of the $D E$-cadherin cDNA sequence published previously (Oda et al. 1994). P34-1 is inserted behind

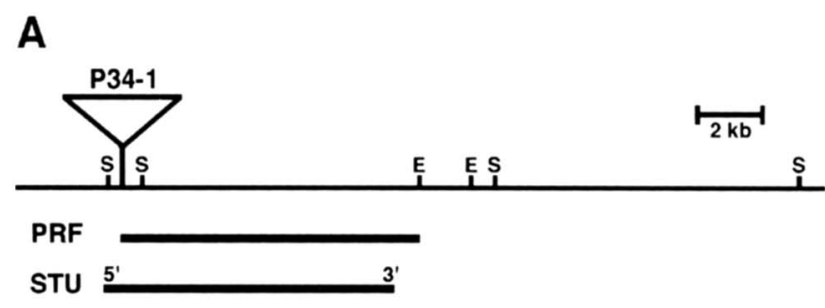

B
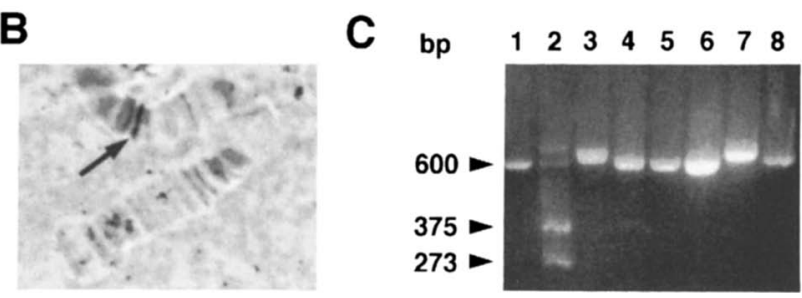

Figure 1. Cloning of shg. (A) Genomic map of the shg locus. $\{\mathrm{E}\rangle$ EcoRI; (S) SalI). The P34-1 PlacW-element is inserted into the 5 '-untranslated region of the shg gene. Indicated are the plasmid rescue fragment (PRF) and the extent of the shg transcription unit (STU) that was mapped by hybridizing oligonucleotide probes that recognize the $5^{\prime}$ and $3^{\prime}$ end, respectively, of the full-length $D E$-cadherin cDNA (Oda et al. 1994). (B) Chromosomal in situ hybridization of the genomic phage clone that contain the STU. The signal (arrow) is located at position 57B13-14. (C) PCR analysis of wild-type revertants of $\operatorname{shg}^{P 34-1}$. (Lane 1) Wild-type control; (lane 2) $\operatorname{shg}^{P 34-1} /$ SM 6 ; (lanes 3-8) six independent homozygous viable revertants. All eight reactions contain three primers; two primers flanking the P34-1 insertion that amplify a 600-bp fragment from wild-type DNA, and a primer that recognizes both ends of the PlacW element. The two smaller bands in lane 2 are the product of the latter primer with either of the flanking primers. The 600 -bp band in lane 2 derives from the wild-type copy of shg on the $S M 6 B$ chromosome (the second band running at $\sim 630 \mathrm{bp}$ seems to be a polymorphism). Note that in all six wild-type revertants, only one band at $\sim 600 \mathrm{bp}$ is amplified. nucleotide 368 of the $5^{\prime}$-untranslated region of the shg cDNA. The shg transcription unit extends over $\sim 11 \mathrm{~kb}$ (Fig. 1A). We studied six wild-type revertants with PCR to confirm the excision of the P34-1 element (Fig. 1C). Our results indicate a precise or near precise excision of P34-1 in all six lines. These results indicate strongly that shg encodes $D E$-cadherin. Consistent with this conclusion, $D E$-cadherin is expressed in tissues that show defects in shg mutant embryos (see below; Oda et al. 1994); these defects have suggested previously to us that shg might encode an epithelium-specific adhesion molecule (Tepass and Hartenstein 1994b). Furthermore, we find that the level of the catenins at the zonula adherens (ZA) is reduced strongly in shg mutant embryos, as expected from a reduction in the level of $D E$-cadherin (see below). Finally, our conclusion is confirmed be results of Uemura et al. (this issue) showing that aspects of the shg mutant phenotype can be rescued by expressing a $D \mathrm{E}$ cadherin cDNA under heat shock control.

\section{shg expression is epithelium specific}

The expression of shg was analyzed by whole-mount in situ hybrydization (Fig. 2). shg is expressed throughout embryogenesis in all epithelial tissues except for the mesoderm and the posterior endoderm. Maternal shg mRNA is deposited in the egg and distributed uniformly in early embryos. During cellularization, shg transcript can be found in all blastoderm cells, but transcript is excluded from the cells of the presumptive mesoderm and endoderm (Fig. 2A) that convert into mesenchymal cells after gastrulation. Mesodermal cells then spread over the inner surface of the ectoderm and reorganize into an epithelial sheet but do not express shg at this stage (Fig. 2C). Later in development two mesodermally derived epithelia, the dorsal vessel (Fig. 2F) and the gonadal sheet, express shg. The endoderm initiates zygotic shg expression just before its cells convert back into epithelial cells that form the lining of the larval midgut and continues to express shg throughout the remainder of embryogenesis (Fig. 2E,F).

The amnioserosa, the ectodermal epithelium, and its epithelial derivatives (epidermis, tracheal system, foregut, hindgut, Malphigian tubules (MTs), salivary glands) express shg continuously. shg is down-regulated in neural precursors while they undergo an epithelial-mesenchymal transition and thereby segregate from the neurectodermal epithelium (Fig. 2D). During later stages, shg mRNA disappears completely in the neural primordium, with the exception of the midline cells and the subperineurial glial sheath (Fig. 2F), a thin epithelium that surrounds the nervous system at late stages of development and forms the blood-brain barrier. Although the main characteristic of the shg expression pattern is clearly the almost ubiquitous expression in epithelial tissues, we detected shg expression in small nonepithelial cell populations, which are neural cells derived from the midline, the lymph gland, and the primordium of the longitudinal visceral muscle of the midgut (data not shown). 


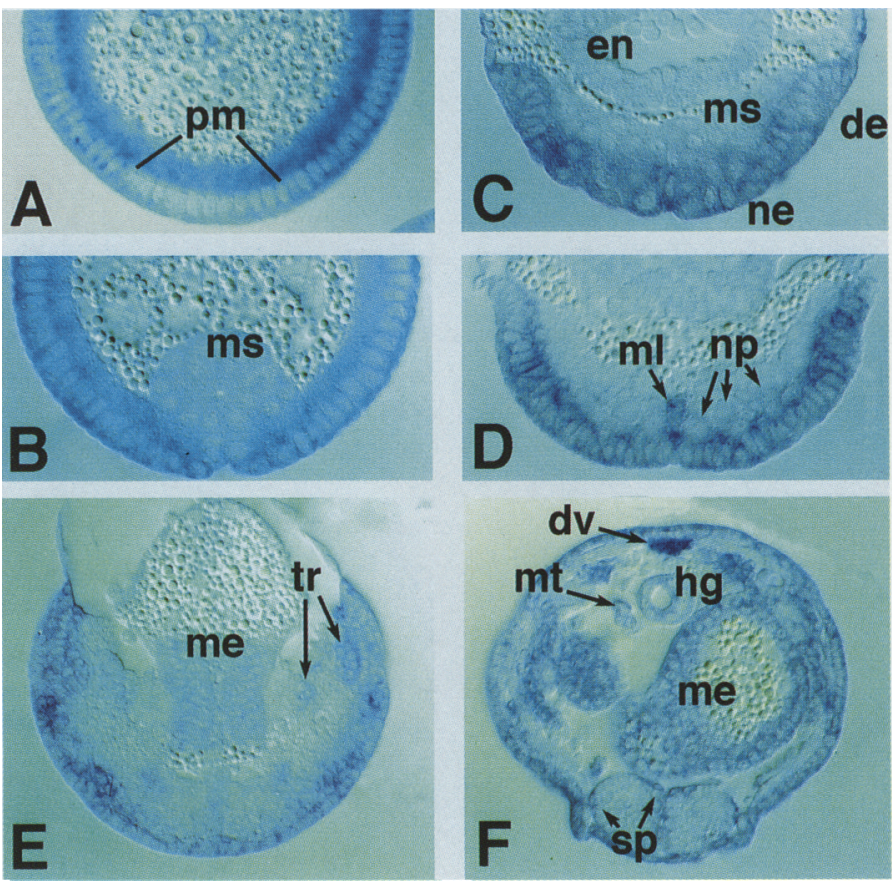

Figure 2. Embryonic shg transcript. $A-F$ show cross-sections of embryos labeled by in situ hybridization. (A) Late syncytial blastoderm (stage 4). Level of shg expression, formerly high in entire blastoderm, decreases in the presumptive mesoderm $(\mathrm{pm}) .(B)$ At the end of gastrulation (stage 7), mesoderm cells (ms) do not express shg and soon will undergo an epithelial-mesenchymal transition. (C) Shortly before neurulation (stage 8), expression is high in the ventral neurectoderm (ne) and dorsal ectoderm (de); expression is absent from the mesoderm and the posterior endoderm (en). (D) After neurulation (stage 11), shg is virtually absent from the neural progenitors (np), except the midline cells ( $\mathrm{ml}) .(E)$ Expression of shg in the midgut primordia as these form the midgut epithelium (me) during stage 12-13. Tracheal branches (tr) are also stained. $(F)$ In mature embryos (stage 17), shg is expressed in the epidermis and all epithelial tissues, including midgut (me), hindgut (hg), dorsal vessel (dv), Malpighian tubules (mt), and subperineurial glia sheath (sp).
Analysis of a phenotypic series reveals a differential requirement for zygotic shg expression in different epithelia

We and others have isolated a large number of mutant shg alleles in various mutagenesis experiments (see Materials and methods). shg alleles are embryonic lethal and most alleles show a phenotype of rather consistent expressivity. These alleles can be placed into a pheno- typic series of increasingly severe mutant defects. Four classes have been defined based of the examination of the larval cutical pattern: (1) Class I alleles (e.g., shgg119) lack portions of the head cuticle and show defects in head involution. The trunk cuticle is intact in these alleles (Fig. 3B). (2) Class II alleles (e.g., shg ${ }^{\mathrm{P} 34-1}$, shg ${ }^{\mathrm{R} 14 \mathrm{a}}$ ) lack most of the head cuticle and have small holes in the ventral cuticle (Fig. 3C). (3) Class III alleles (e.g., shg ${ }^{\mathrm{IH}}$, $s h g^{\mathrm{R} 64 \mathrm{a}}$ lack most of the head and ventral epidermis
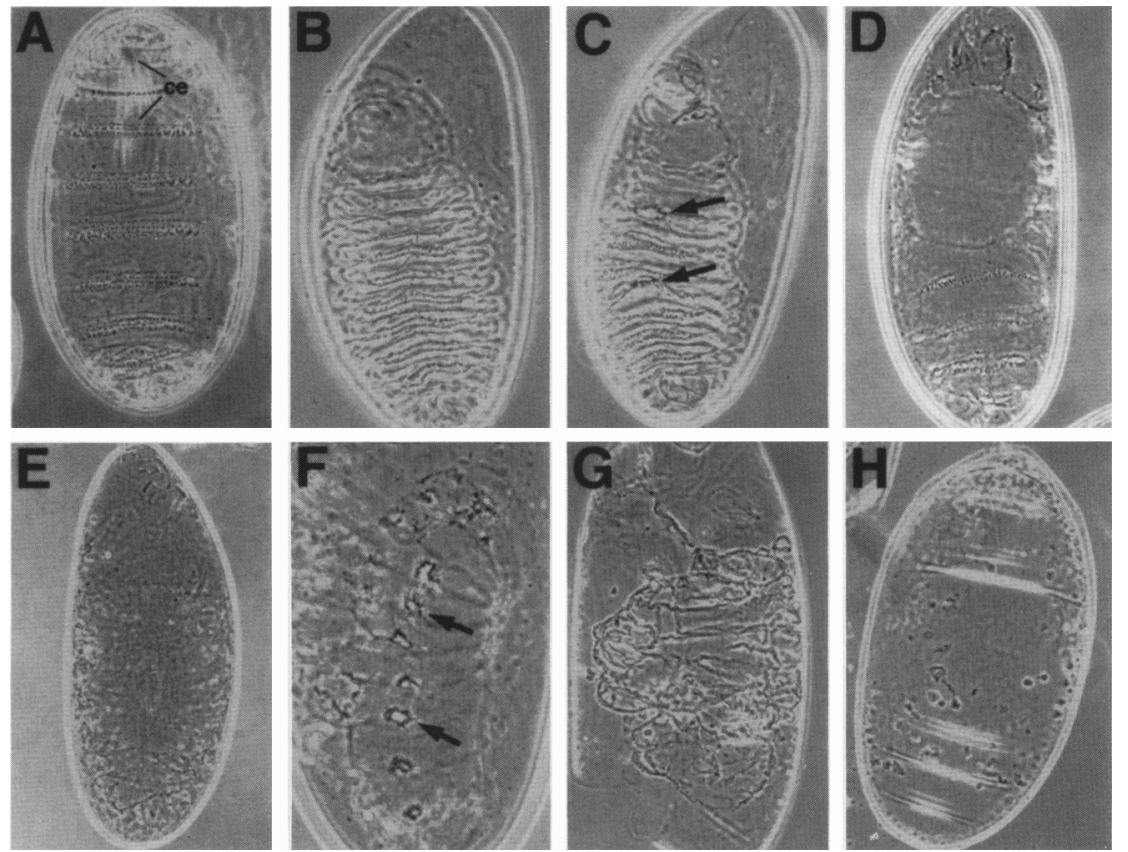

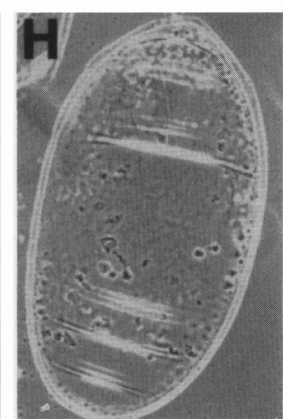

Figure 3. Cuticle defects observed in shg mutant embryos. $(A)$ Ventral view of wildtype cuticle preparation showing denticle belts and cephalopharyngeal skeleton (ce), a specialized cuticle secreted by the head epidermis. (B) Class I allele $\left(\operatorname{shg}^{g 119}\right)$ cause defects of the cephalopharyngeal skeleton; the cuticle of the trunk segments forms normally. (C) Class II allele $\left(\operatorname{shg}^{\text {P34-1 }}\right)$, shows absence of the cephalopharyngeal skeleton and holes in the ventral cuticle (arrows). (D) $s h g^{I H}$, a class III allele representing the zygotic null phenotype, exhibits loss of head and most of the ventral cuticle. $(E) s h g^{g 317}$ represents class IV alleles with stronger defects than the zygotic nulls. The head and ventral cuticle are completely missing. $(F)$ Lateral cuticle of shg ${ }^{g 317}$ shows segmentally reiterated holes at positions of dense clusters of lateral sense organs (arrows). (G) Cuticle of $s h g^{g 119}$ germ-line clone. In addition to head and ventral cuticle, large parts of dorsal cuticle is also deleted. $(H)$ shg $^{P 34-1}$ germ-line clones show an almost total absence of cuticle. 
$(\sim 50 \%-70 \%)$ (Fig. 3D). This class represents genetic null alleles because in homozygosis these alleles show the same severity of phenotype as in hemizygosis over the shg deficiency $D f(2 R) D 17$. (4) Class IV alleles (e.g., shgg317, sh $g^{\mathrm{I} 2 \mathrm{~B} 2}$ / show a phenotype that is substantially stronger than the apparent zygotic null phenotype (class III). These alleles lack all of the head and ventral cuticle (Fig. 3E). Some alleles in this class show segmental defects in the lateral epidermis (Fig. 3F), whereas others lack substantial portions of the lateral and dorsal epidermis in addition to the ventral epidermis. We speculate that these alleles are dominant-negative alleles that reduce the function of the maternal contribution of shg expression (see below). Class IV alleles do not reveal any novel phenotypic trait compared with other shg alleles and when crossed over a shg deletion, show a weaker phenotype corresponding more to that of a class III allele. This is consistent with the dose-dependent activity of a dominant-negative allele. Vertebrate classic cadherins that lack the extracellular or the intracellular domain also behave as dominant-negative mutations (Kintner 1992; Levine et al. 1994), suggesting that class IV alleles might carry specific defects in either of these two portions of the $D E$-cadherin protein.

The phenotypes of embryos transheterozygous for representative alleles of different classes were examined in all possible combinations. Such embryos showed phenotypes that were intermediate to the homozygous phenotype of either allele confirming that our classification of shg alleles reflects a series of decreasing shg activity. The analysis of shg alleles indicates that the level of shg function required for normal development varies in different epithelia. This level appears to be highest in the procephalic neurectoderm, because the head cuticle that derives from this region is affected even in weak alleles that otherwise develop normally. Most striking is the difference between the ventral and dorsal epidermis in the trunk. Although both tissues express similar amounts of shg transcript (Fig. 2) and protein (Oda et al. 1994), the ventral epidermis is mostly or entirely deleted in strong alleles (classes III and IV), whereas the dorsal epidermis differentiates normally. Strong alleles also show holes in the lateral epidermis at positions where sensory structures are located (Fig. 3F; see below). In addition, defects in the tracheal system are apparent in cuticle preparations of class III and IV alleles. The defects include the failure of the segmental tracheal units to fuse into a continuous tracheal trunk and a failure of the posterior spiracle to invaginate (data not shown). Excluding the lateral and dorsal ectoderm, most parts of the foreand hindgut are resistant to loss of zygotic shg expression.

Maternal shg expression is required for oogenesis and embryogenesis

The presence of maternal shg mRNA in early embryos suggests that shg may have a maternal component of expression that is relevant for embryogenesis. Germ-line clones of several shg alleles were generated to address this question (see Materials and methods). For class III and IV shg alleles $\left(s h g^{\mathrm{IH}}\right.$; shg $\left.{ }^{\mathrm{g} 317}\right)$ no eggs were recovered, suggesting that shg is essential for oogenesis. For the weaker alleles shg ${ }^{\mathrm{g} 119}$ (class I) and shg ${ }^{\mathrm{P} 34-1}$ (class II) only few fertilized eggs were recovered, many of which had cuticle defects comparable to class III and IV alleles (Fig. $3 G)$. Several embryos exhibited defects that were substantially stronger than those caused by class IV alleles. In these embryos, the remains of all cuticle-secreting epithelia (epidermis, tracheal system, foregut, hindgut) were reduced to small patches and threads of cuticle (Fig. $3 F$ ), a phenotype reminiscent of the phenotype caused by strong $c r b$ mutations (Tepass and Knust 1990). Although we were unable to study embryogenesis in the total absence of shg function, it seems likely that in such a case the development of the mentioned epithelia would be disrupted entirely. These results show that maternal shg expression is essential for embryogenesis and reveal a function of shg in tissues that do not require zygotic shg expression, such as the dorsal epidermis.

\section{shg is preferentially required in the neurectoderm and other morphogenetically active epithelia}

To elucidate the cause for the remarkable difference in sensitivity of various epithelia toward reduction of $s h g$ function, we studied the development of shg mutant embryos in more detail. Our results demonstrate a correlation between the appearance of defects and morphogenetic movements taking place at that time and place. Among the epithelia whose development is affected most by the reduction or loss of shg function are the neurectoderm, MTs, and the midgut epithelium. Epithelial integrity is lost in these tissues at a stage when they undergo dramatic morphogenetic movements that involve cellular rearrangements. Such morphogenetic movements include delamination, invagination, and convergence-extension processes. In contrast, morphogenetically less active epithelia are more resistant to reduction of shg function. Most striking is the difference between the ventral neurectoderm and the adjacent dorsal ectoderm. In wild type, about one-quarter of neurectodermal cells scattered at rather regular intervals delaminate, thereby losing contact to their neighbors and sliding out of the ectodermal epithelium to form internally located neuroblasts (Hartenstein and CamposOrtega 1984; Doe 1992; Hartenstein et al. 1994a). The remaining cells close the gaps left by the delaminating neuroblasts as they form and give rise to the ventral epidermis. In shg, the epidermal precursors break up into irregular clusters of rounded cells (Fig. 4B,C). Gaps form between these clusters so that the neural primordium is exposed at the outer surface of the embryo (Fig. 4J). These defects first appear toward the end of neuroblast delamination (stage10) in some parts of the procephalic neurectoderm and ventral neurectoderm. In the latter, they are more frequent close to the midline and at the posterior pole of the embryo (Fig. $4 \mathrm{H}, \mathrm{I}$ ). Throughout neuroblast segregation the dorsal ectoderm develops normally. 


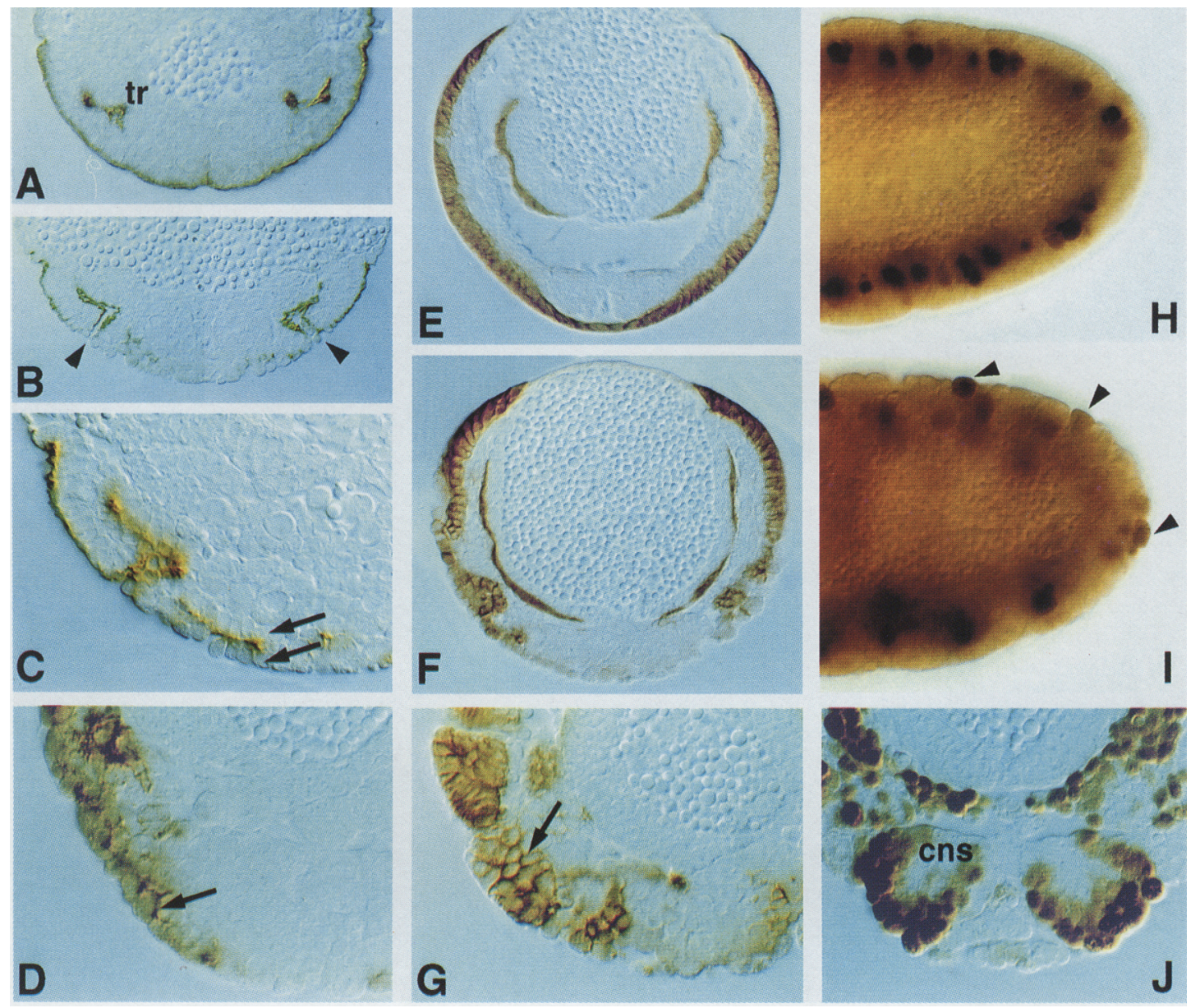

Figure 4. Defects in the neurectoderm of shg mutants. $(A)$ Section of stage 12 wild-type embryo, stained with a marker of the apical membrane of epithelia, anti-Crb. Continuous band of apical staining is observed in the entire ectoderm and invaginated tracheal pits (tr). The region between the tracheal pits corresponds to the ventral neurectoderm from where progenitors of the central nervous system (CNS) (not stained) have segregated earlier. $(B)$ In shgg317 of comparable age, continuity of anti-Crb staining is lost in the ventral neurectoderm (between arrowheads) as cells round up and form clusters. In contrast, staining of the tracheal pits and dorsal ectoderm is normal. (C) Section of $s h g^{g 317}$ embryo at higher magnification, showing polarized expression of Crb in irregularly clustered neurectoderm cells (arrows). (D) Section of late (stage 16) shg ${ }^{3.317} \mathrm{Df}(3 \mathrm{~L}) \mathrm{H} 99$ double mutant embryo, showing Crb expression in irregularly clustered epidermal cells that were rescued from apoptosis. Note that Crb is still expressed in a polarized manner, although many cells have lost their proper orientation (arrow). (E) Section of stage 14 wild-type embryo labeled with anti-Fas III, a marker of the basolateral membrane of ectodermal cells. $(F)$ In shg ${ }^{g 317}$, irregularly clustered ventral ectodermal cells still show polarized Fas III expression, although overall level of this marker is reduced significantly. $(G)$ Section of late (stage 15) shg ${ }^{3317}$ Df(3L)H99 double mutant embryo, showing polarized Fas III expression in ventral epidermis (arrow). $(H)$ Posterior pole of wild-type stage 10 embryo, lateral view, expressing $s v p$ lacZ in groups of delaminated neuroblasts. (I) In shg $g^{317}$ of comparable age, several neuroblasts are at the surface as gaps start to appear in the surrounding ectodermal cells (arrowheads). The defects are most pronounced at the posterior pole (right) where the germ band is curved around, possibly subjecting ectoderm cells to increased mechanical stress. (J) Section of late (stage 15) shgg317 embryo expressing svp lacZ in part of the CNS and other cells. The CNS is exposed to the outer surface as ventral epidermis has undergone apoptosis.

After losing their regular epithelial arrangement, most cells of the epidermal primordium in shg mutant embryos undergo programmed cell death. To rule out the possibility that imminent cell death is responsible for the loss of epithelial integrity, we examined the shg phenotype in the background of a mutation that suppresses cell death $(D f(3 L) H 99$; White et al. 1994). Although cell death is suppressed completely in shg $D f(3 L) H 99$ double mutants, the epithelial breakdown still occurs to the same extent as in shg mutant (Fig. 4D,G).

Despite of the severe defects in shape and spatial arrangement caused by loss of shg function, neurectoderm cells continue to express signs of polarization and cytodifferentiation. This was assayed by staining double mutant shg $D f(3 L) H 99$ embryos with an antibody against the apically expressed Crb protein (Tepass et al. 1990) and 
the basolaterally concentrated Fasciclin III (Fas III) protein (Patel et al. 1987). Both markers are still expressed in a polarized fashion in many cells of the irregular clusters that make up the neurectoderm of the mutant embryos, suggesting that the loss of $s h g / D \mathrm{E}$-cadherin leads to a specific defect causing the collapse of the epithelial tissue structure.

Many sensory organ precursors (SOPs) also delaminate from the ectoderm. A particularly large number of SOPs, among them those giving rise to the lateral chordotonal organ, delaminate from within a small region in the lateral ectoderm. Consistent with their phenotype in the ventral neurectoderm, strong shg alleles show defects at positions where SOPs delaminate, resulting in clusters of sensory neurons exposed at the outer surface (Fig. 5B). However, in spite of their abnormal position, sensory neurons extend axons and dendrites and chordotonal organs form normal scolopidia (Fig. 5B,D). Ultrastructurally, the cytodifferentiation of sensory organs appears to be normal (see Fig. 8C,D, below).

Besides epithelia from that cells delaminate, other epithelia affected by loss of shg function are those whose cells invaginate and/or undergo convergence-extension movements. Among these tissues are the precursors of the optic lobe, stomatogastric nervous system (SNS), and MTs. The SNS precursors develop as epithelial cells that normally invaginate as pouches from the foregut (Hartenstein et al. 1994a). In strong shg alleles, these pouches detach prematurely from the surrounding cells. Most cells of the SNS form an irregular cluster of rounded cells with discontinuous Crb expression that is sequestered into the lumen of the foregut (Fig. $5 \mathrm{~F}, \mathrm{H}$ ). Similar defects were found during optic lobe development. Despite their severe morphogenetic defects, the cells of the SNS and the optic lobe differentiate properly as neurons (data not shown). The MTs normally form as invaginations of the hindgut and subsequently elongate dramatically by means of convergence-extension movements (Skaer 1993). In shg mutants the MTs separate from the hindgut epithelium during their invagination and the subsequent convergence-extension movement is blocked. Therefore, the epithelium of the MTs collapses into a pile of small cell clusters with patchy $\mathrm{Crb}$ expression (Fig. $6 \mathrm{H}, \mathrm{J})$. In contrast to the neurectoderm, the MTs show no signs of cell death in shg mutants.

\section{Decreasing morphogenetic activity in a tissue reduces its requirement for shg function}

To test the hypothesis that the requirement for shg function is correlated with the level of morphogenetic activity in a given epithelium, we used genetic tools to reduce morphogenetic activity in two epithelia-the neurectoderm and the MTs-and assayed for changes in their response to reduction of shg function. It has been shown that the expression of an activated form of the transmembrane receptor Notch, that is achieved by overexpression of the cytoplasmic domain of the Notch $\left(N_{\text {intra }}\right)$, blocks neural progenitor development (Lieber et al. 1993; Rebay et al. 1993; Struhl et al. 1993). Notch is part of a
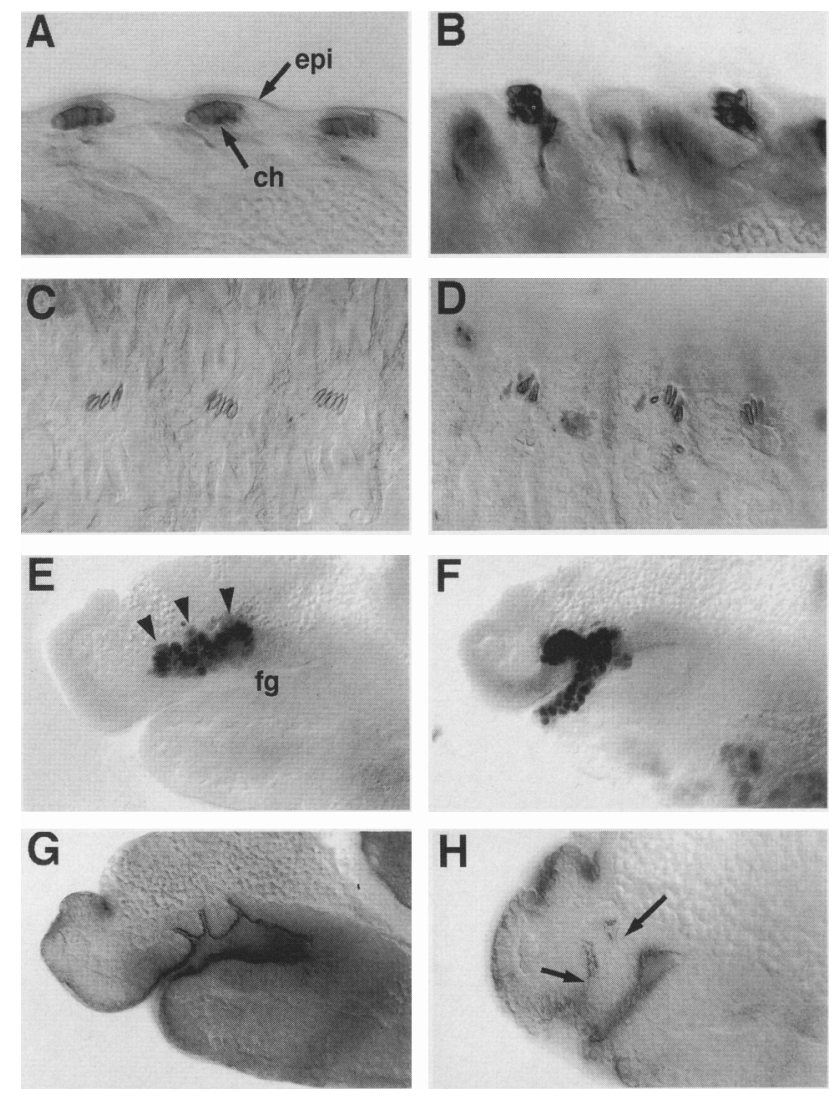

Figure 5. Peripheral nervous system (PNS) and SNS defects in shg mutants. $(A-D)$ Sensory organs. $(A)$ Wild-type embryo, stage 16 , showing sensory neurons of chordotonal organs (ch) stained with MAb 22Cl0. All neurons are located underneath the epidermal layer (epi). (B) In shggit embryo of comparable stage, clusters of lateral sensory neurons are exposed to the surface, following dissociation of surrounding epidermal cells. $(C)$ Differentiated sensilla of chordotonal organ type show high levels of Crb expression surrounding sensory dendrites in wild type. (D) Despite of their abnormal position at the surface, chordotonal organs in $s h g^{g 317}$ differentiate and show the same peridendritic Crb accumulation. $(E-H)$ SNS. $(E, G)$ In wild-type embryos (stage 12), precursors of the SNS labeled by PlacZ 94 in E, segregate as three invaginations (arrowheads) from the foregut (fg). Cells of the SNS invaginations remain epithelial, shown by their continued polarized Crb expression $(G) .(F, H)$ In $s h g^{I H}$ mutant of comparable age, SNS invaginations lose continuity with foregut epithelium. Many SNS cells are displaced into lumen of foregut. Premature separation of the SNS pouches from the foregut epithelium can be seen in anti-Crb stained embryos (arrows in $H$ ).

network of genes that control the specification of neural and epidermal precursor cells in the neurectoderm /Campos-Ortega 1993). Notch loss of function causes all cells of the neuroectoderm to develop as neural precusors. Uniform activation of Notch, on the other hand, causes all cells to remain in the neurectodermal epithelium and develop as ventral epidermal precursors. Thus, in $N_{\text {intra }}$ there are still two epidermal domains, a ventral and a dorsal, but the ventral domain does not release any neu- 
roblasts and thereby shows a degree of morphogenetic activity that now resembles that of the dorsal epidermis. To test our conjecture that the delamination of neural precursors is responsible for the high requirement for shg expression in the neurectoderm, we expressed $N_{\text {intra }}$ in the background of a strong shg allele. In these embryos the shg mutant phenotype is substantially reduced (Fig. 6A-E). Most of the ventral epidermis could be rescued, although pronounced defects in the procephalic ectoderm still occurred. This finding suggests that by preventing neuroblast delamination (and thereby transforming the ventral neurectoderm into a morphogenetically inactive epithelium similar to the dorsal epidermal primordium) the requirement for shg function is reduced.

The interaction between shg and $N_{\text {intra }}$ might be a tissue-specific or gene-specific effect. To rule out this possibility, we conducted a similar genetic manipulation to alter morphogenetic activity in a different tissue: the MTs that shows strong defects in shg mutants. Loss-offunction alleles of the gene cut $(\mathrm{ct})$ prevent the convergence-extension movement of the MTs but do not affect the specification of the cells of the MTs (Liu and Jack 1992; Skaer 1993). The MTs do not clongate and instead remain as a short, thick outgrowth of the hindgut whose wall consists of columnar epithelial cells (Fig. $6 \mathrm{H}$ ). In $c t$ shg double mutants, the fragmentation of the MTs typical for shg alone does not occur; the MTs appear similar as in $c t$, that is, as plump epithelial pouches of columnar cells (Fig. 6I). This indicates that by preventing the convergence-extension movement that normally leads to the elongation of the MTs, zygotic shg function becomes obsolete.

Reduction of shg function leads to dissociation of catenins from the membrane but leaves the $Z A$ intact

The vertebrate cadherin-catenin complex is concentrated at the ZA. E-cadherin function is crucially involved in organizing this membrane specialization; blocking E-cadherin function in cultured epithelial cells leads to the breakdown of the ZA (Rodriguez-Boulan and Nelson 1989|. DE-cadherin forms a complex with $D \alpha$ catenin and Arm that, similar to its vertebrate counterpart, is concentrated at the ZA (Peifer 1993; Oda et al. 1994; U. Tepass unpubl.). Using antibodies against both catenins we analyzed the localization of these proteins in class III and IV shg alleles. An intense staining of the ZA is seen in epithelia of wild-type embryos with both $D \alpha$-catenin and Arm antibodies. This staining is strongly reduced or absent is shg mutant embryos even in those cells that appear structurally normal, for example, the hindgut (Fig. 7D), the dorsal epidermis (Fig. 7F), or the chordotonal organs (Fig. $7 \mathrm{H}$ ). Surprisingly, despite the dissociation of catenins from the membrane, the ZA in dorsal epidermal cells is left intact on the ultrastructural level (Fig. 8A,B). The chordotonal organs show a normal ultrastructural differentiation (Fig. 8C,D). These findings suggest that a ZA can form even if the level of $D E$-cadherin-catenin complexes at the membrane is reduced
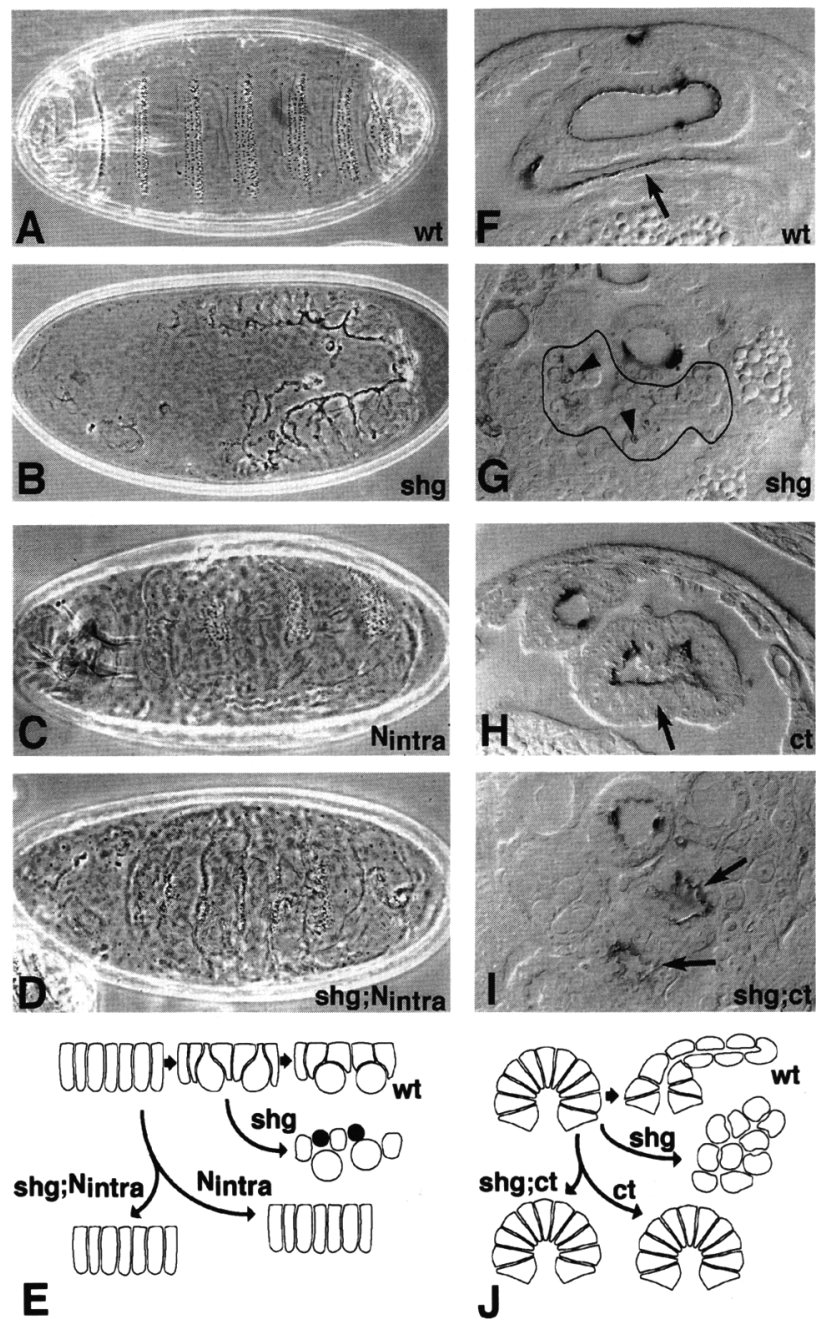

Figure 6. Rescue of shg mutant phenotype in neurectoderm and MTs by reduction of morphogenetic activity. $(A-D)$ Cuticle preparations (ventral view) of wild type $(A)$, shgg ${ }^{\text {g317 }}(B), N_{\text {intra }}$ heat-shocked from 3:30-6:30 hr $(C)$, and shg ${ }^{3317} N_{\text {intra }}$ double mutant $(D$; same heat shock regimen as in $C)$. (E) Schematically depicts neurectodermal structure in the four genotypes shown in $A-D$. $s h g^{g 317}$ is characterized by complete absence of ventral cuticle $(B)$. Heat-shocking of $N_{\text {intra }}$ embryos prevents neuroblast delamination, but leads to an essentially normal cuticle pattern $(C)$. In the double mutant $(D)$, ventral cuticle defects are significantly milder than in $\operatorname{shg} g^{g 317}$ alone, as can be seen by presence of denticle belts. $(F-I)$ Sections of late embryos (stage 16) in that apical membranes of hindgut and MTs are labeled with antiCrb. $(J)$ schematically depicts structure of MTs in the four genotypes shown in $F-I$. In wild type $(F)$, MTs form slender epithelial tubes (arrow). In shgg317 (G), MT cells form multiple small clusters of cells (outline) with patchy Crb expression (arrowheads). In ct mutants $(H)$, elongation of MTs is blocked; cells form epithelial sac (arrow) composed of columnar cells. shg ${ }^{g 317}$ ct double mutants $(I)$ show a phenotype similar to $c t$ alone (arrows).

strongly. In the MTs, an epithelium strongly disrupted in shg mutants, we find microvilli and patchy adherens junctions at one cell pole, indicating that aspects of epithelial polarity are still found in these cells (Fig. 8E,F). 


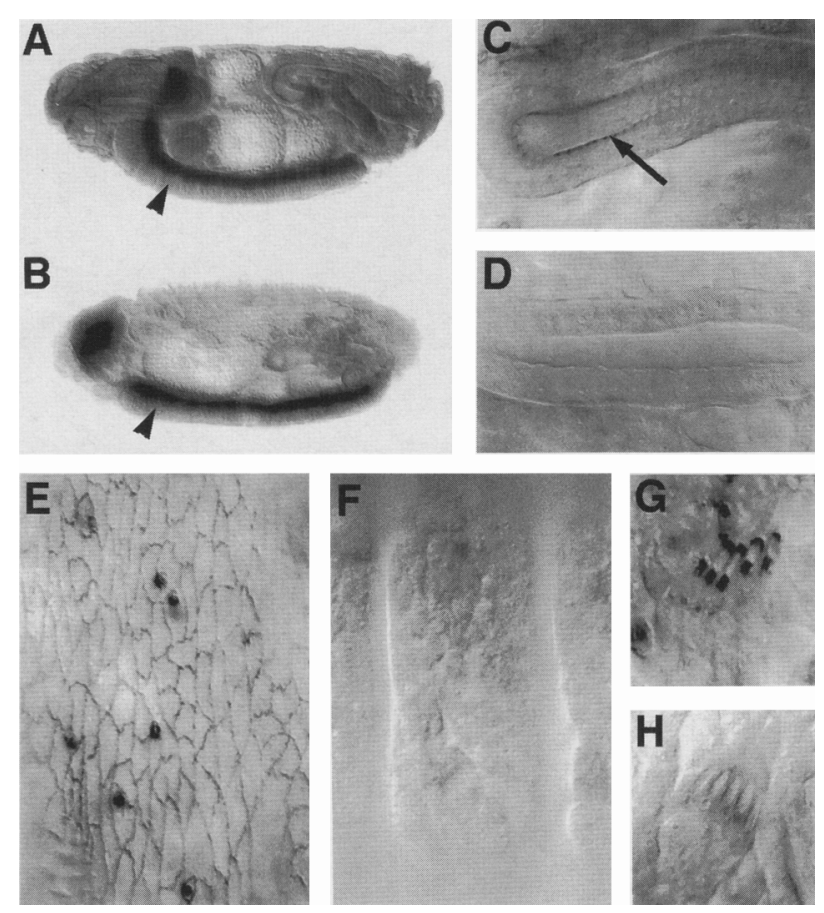

Figure 7. Loss of shg function leads to strong reduction of membrane-bound $D \alpha$-catenin and Arm. In mature wild-type embryos $(A, C, E, G), D \alpha$-catenin is present in the neuropile of the CNS (arrowhead in $A$ ) and all epithelial cells where it is concentrated in ZA surrounding the apical cell pole $\left(C_{\text {; }}\right.$ arrow showing apical band of staining in hindgut). Arm shows similar accumulation in ZA of epidermal $(E)$ and sensillum cells $(G$; showing staining in scolopidial cells of lateral chordotonal organ). In shg ${ }^{g 317}$ mutant $(B, D, F, H), D \alpha$-catenin is still expressed at a high level in the neuropil (arrowhead in $B$ ) but is strongly reduced or absent from the ZA of epithelial cells (shown for hindgut in $D$ ). The same reduction is observed for Arm in epidermis $(F)$ and sensillum cells $(H)$.

\section{Discussion}

The results of this paper show that $D E$-cadherin is encoded by the shg locus and that high levels of $s h g-D \mathrm{E}-$ cadherin expression are required for the stability of morphogenetically active epithelia, such as the different parts of the neurectoderm or the MTs. In shg mutant embryos, epithelial integritity is lost in these tissues when they undergo morphogenetic movements, such as delamination, invagination, or convergence-extension. In contrast, epithelia that appear more static, relatively speaking, (e.g., the dorsal ectoderm) require only a low level of shg function and break down only when both maternal and zygotic shg expression is removed.

The activity of the shg promoter, that was assayed by the lac $Z$ reporter gene contained in the P34-1 line /data not shown/ and by detection of shg transcript, is predominantly epithelium-specific and suggests that $D E$-cadherin is the major epithelial cadherin in Drosophila embryos. In late embryos, all epithelia without exception express shg. In early embryos, shg is expressed in the ectoderm, but not the posterior endoderm and meso- derm, that transiently also form epithelial structures, suggesting that these tissues might express a different cadherin. In vertebrates, the epithelial somites, that are mesodermal in origin, express $\mathrm{N}$-cadherin instead of E-cadherin (Takeichi 1988).

A conspicuous difference between vertebrates and Drosophila is that shg-DE-cadherin is expressed in both the neurectoderm and non-neurogenic ectoderm, whereas in vertebrate embryos $\mathrm{N}$-cadherin replaces E-cadherin in the neurectoderm. The appearance of $D E$ cadherin in both neurogenic and non-neurogenic ectoderm may be related to the fact that the segregation of neural and epidermal progenitors in Drosophila proceeds differently from that one in vertebrates. In vertebrates, the neurectoderm contains only neural progenitors that invaginate and, after physically separating from the nonneurogenic ectoderm, form the neural tube that expresses N-cadherin. This observation suggested that differential expression of $\mathrm{E}$-cadherin and $\mathrm{N}$-cadherin is required for the separation of the neurectoderm from the non-neurogenic ectoderm. Experiments in which-after expressing $\mathrm{N}$-cadherin in both neurectoderm and epidermal ectoderm-the separation of these tissue layers was disrupted (Detrick et al. 1990; Fujimori et al. 1990) support this hypothesis. In Drosophila, the neurectoderm is formed by a mixture of both neural and epidermal progenitors and does not physically separate from the adjacent non-neurogenic ectoderm, that contains only epidermal precursors. After neural progenitors have delaminated, the remainder of the neurectoderm forms a continuous epithelium that develops into the epidermis. Therefore, no apparent need exists for the differential expression of different cadherin isoforms.

A characteristic feature of classic cadherin expression is their down-regulation during epithelial-mesenchymal transitions (Takeichi 1988, 1991). shg/DE-cadherin behaves similarly during the delamination of neural progenitors. The segregation of these cells from the remaining ectoderm, that will form the epidermis, is controlled by the neurogenic and proneural genes (for review, see Campos-Ortega 1993). The delamination of neural precursor cells is the immediate consequence of the upregulation of proneural gene activity in these cells; in neigboring cells that remain epithelial, proneural genes are down-regulated. It is possible that the proneural genes that encode transcriptional regulators of the basic helix-loop-helix family are directly responsible for the decrease in shg promoter activity. Such an interaction would link the activity of proneural genes directly to the mechanisms that control cell morphology, and it would corroborate our model (Tepass and Hartenstein 1995) that neurogenic and proneural genes control the segregation of cells with epithelial versus mesenchymal structure.

The function of shg appears to be required generally to maintain epithelial integrity. All cuticle secreting epithelia, comprising the entire epidermis, trachea, and fore- and hindgut, break down following the removal of both maternal and zygotic shg expression. Similar to arm (Peifer et al. 1993), shg is apparently required for oogen- 

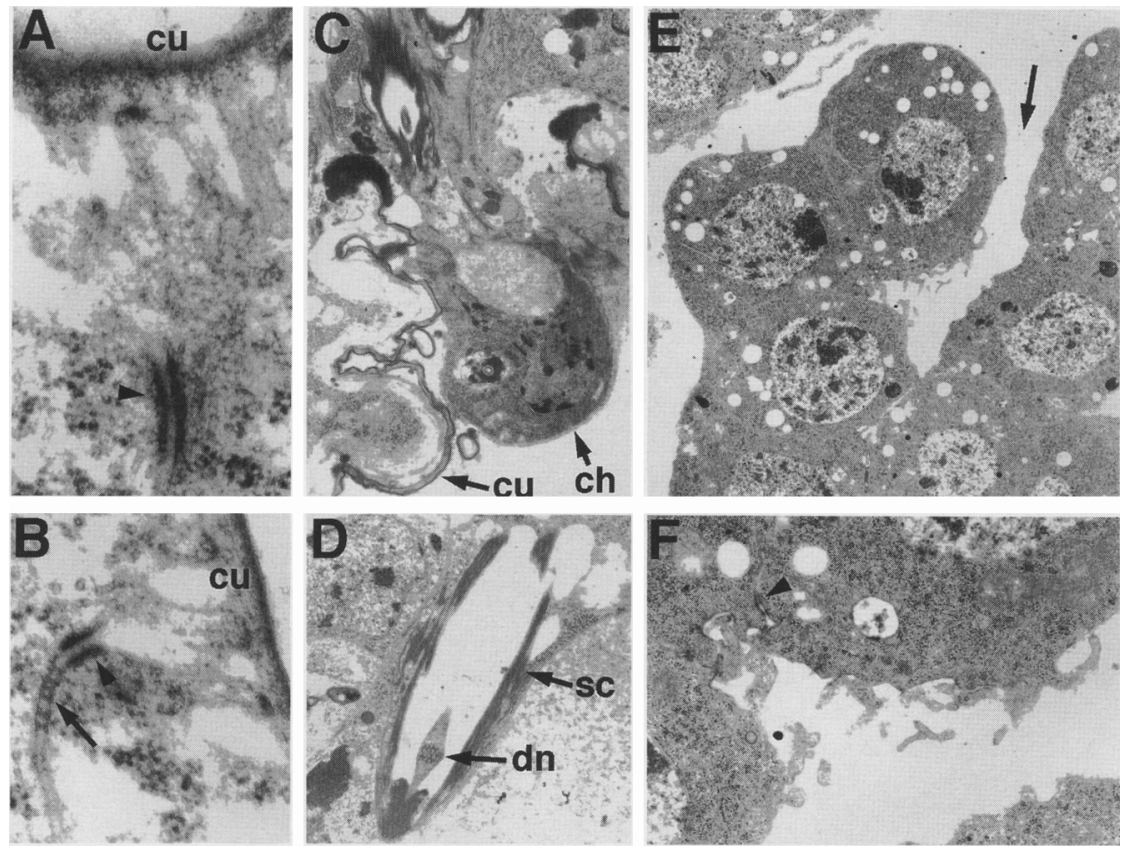

Figure 8. The ZA of many epithelial cells is unaffected by zygotic loss of shg function. Transmission electron microscope micrographs of thin sections of lateral epidermis $\langle A, B|$, chordotonal organ $(C, D)$, and MT $(E, F)$ of mature shg ${ }^{g 317}$ embryo. $(A, B)$ Normal looking junctional complex comprising ZA (arrowheads) and septate junctions (arrow) can be distinguished. $|C, D|$ Cells of the chordotonal organ (ch) protrude through a gap in the lateral cuticle (cu). Despite this defect, many aspects of cytodifferentiation of these ectopically located sensory cells, such as formation of a ciliary dendrite ( $\mathrm{dn}$ ) and a scolopale (sc), are normal. $(E, F) \mathrm{MT}$ cells form small clusters and the lumen has opened up (arrow in $E$ ). Aspects of polarity are still present, such as apical adherens junctions (arrowhead in $F$ ) and patches of microvilli $(F)$. esis. We recovered a reduced number of fertilized eggs only from germ-line clones of class I and II alleles. Of these embryos, $\sim 50 \%$ developed defects that are substantially stronger as the zygotic defects seen in these alleles. Some of these embryos lacked recognizable cuticle structures altogether, suggesting that $s h g / D E$-cadherin is required in all tissues where it is expressed. This conclusion is supported by the finding that some of the class IV alleles that we believe to be dominant-negative alleles, show a reduction in the lateral and dorsal epidermis and more severe defects in the gut and tracheal system as zygotic null alleles. In embryos that lack only zygotic shg expression, defects appear after most organ primordia have already formed, and they affect only a subset of epithelia including the neurectoderm, MTs, SNS and optic lobes (this study), and the midgut epithelium (Tepass and Hartenstein 1994b). Early morphogenetic movements proceed normally in these embryos, although $D E$-cadherin, $D \alpha$-catenin, and Arm are expressed from cellularization, the stage when the first adherens junctions form, onwards (Riggleman et al. 1990; Oda et al. 1993, 1994; Tepass and Hartenstein 1994a; U. Tepass, unpubl.|. It is likely that maternal shg expression is sufficient to support normal development during early embryonic stages.

A closer developmental analysis of embryos that lack zygotic shg expression shows that the epithelia affected have in common that they undergo morphogenetic movements involving cell rearrangements and/or mechanical stress. For example, the ventral neurectoderm collapses at a time when $\sim 25 \%$ of its cells delaminate as neural progenitors (Hartenstein and Campos-Ortega 1984; Doe 1992). During delamination, adhesive contacts to neural progenitors are disrupted and new contacts among the epidermal progenitors that remain epi- thelial have to be established to maintain the epithelial sheet. Likewise, the MTs of shg embryos collapse when their cells rearrange to form elongated, narrow tubes by convergence-extension. We have decribed previously that shg function is needed during midgut development at a stage when mesenchymal precursors rearrange to form the midgut epithelium (Tepass and Hartenstein 1994b). To confirm our notion that the morphogenetic movements are the primary cause necessitating high levels of shg expression, we have blocked these movements in the neurectoderm and the MTs and found that this manipulation rescues the shg mutant phenotype in these tissues. Taken together, our observations demonstrate that continuous shg expression is essential to maintain epithelial integrity during cell rearrangement processes.

Although we can not entirely rule out the possibility that shg has a specialized role in morphogenetically active epithelia, we believe that the differences in shg requirement between morphogenetically active and inactive epithelial are quantitative rather than qualitative in nature. Our observations support a model that assumes that once an adhesive contact between neighboring cells has broken up, the DE-cadherin molecules are degraded and not reutilized to establish a new contact to a different cell (Fig. 9). During embryogenesis, the maternally supplied DE-cadherin is apparently turned over in all epithelia including morphogenetically inactive epithelia such as the dorsal epidermis. This can be concluded from our observation that in all epithelia the cadherin-catenin complex is undetectable in late shg mutant embryos. In epithelia that undergo cell rearrangments, it is likely that the turnover rate of the complex is even higher because cells detach from each other and adherens junctions have to be broken up completely. We speculate that in these tissues maternally supplied $D E$-cadherin is 


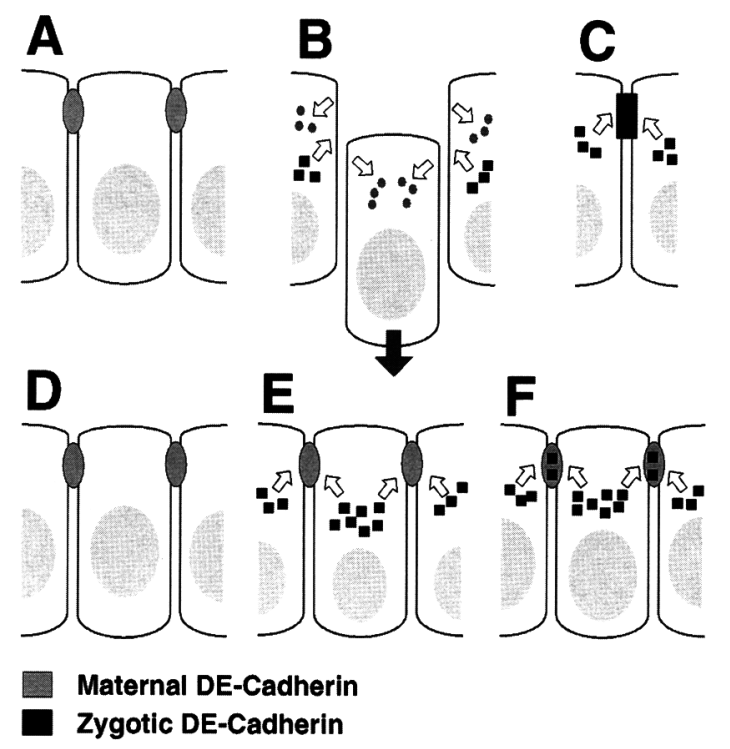

Figure 9. Model for $s h g / D E$-cadherin function. In morphogenetically active epithelia $(A-C)$, maternally provided $D E$-cadherin $|A|$ is withdrawn from the membrane as cell contacts break down during movements $(B)$. Zygotic expression of $D \mathrm{E}$ cadherin is required during formation of new cell contacts $(C)$. In less active epithelia $(D-F)$ in that cell contacts do not break down, maternally provided $D E$-cadherin $(D)$ is sufficient for maintaining tissue integrity. Zygotic $D E$-cadherin is added to these junctions $(E, F)$.

replaced to a higher degree than in morphogenetically inactive tissues so that in the absence of zygotic shg expression, these tissues lose their epithelial integrity. In contrast, in more static tissues like the dorsal epidermis, replacement of maternal $D \mathrm{E}$-cadherin by zygotic $D \mathrm{E}$-cadherin is not crucial, so that these tissues remain intact even if zygotic shg expression is absent. Nevertheless, we find it very surprising that a dramatic reduction in the concentration of the cadherin-catenin complex in tissues like the dorsal epidermis is compatible with normal tissue differentiation and particularly the presence of an ultrastructurally normal ZA.

A second aspect of morphogenesis that might contribute to the development of defects in shg mutant embryos is mechanical stress. Mechanical stress could be responsible for the ruptures occuring in invaginating cell populations in shg mutant embryos. Such ruptures are particularly evident along the boundaries between small invaginations (e.g., SNS, MTs) and the surrounding epithelium. The cells situated at these boundaries are pulled inward by the invaginating cells and, at the same time, have to maintain contact to the surrounding stationary epithelium. Torn between the two cell populations, these cells may depend on a higher amount of adhesion molecules, that would explain their requirement of zygotic shg function. Similarly, in the ventral neurectoderm, defects first appear at the posterior pole of the embryos during the extended germ-band stage (abdominal segments $2-5$ ) where cells are more stretched out compared with the remaining ventral neurectoderm. Mechanical stress might also occur on the single-cell level during cell rearrangements and might compound the effect of a higher turnover rate of $D E$-cadherin.

The model presented in Figure 9 suggests that the cadherin-catenin complex is dynamically regulated during cell rearrangement and implies that transiently, during the breakup and reformation of adherens junctions, the degree of intercellular adhesion is reduced. This assumption is corroborated by a report on C-cadherin requirement during the convergence-extension movements observed in Xenopus animal caps in response to activin induction (Brieher and Gumbiner 1994). Although the level of C-cadherin at the cell surface does not change upon induction, the degree of C-cadherin-mediated adhesion was found to be reduced, suggesting that a reduced level of intercellular adhesion exists in a tissue that undergoes cell rerrangement. Recent studies suggest that $\beta$-catenin might be the key regulatory component of the complex. $\beta$-Catenin apparently mediates the interaction between E-cadherin and $\alpha$-catenin (Hülsken et al. 1994/ and at the same time dynamically regulates the catenin-cadherin complex. A fusion protein that covalently links E-cadherin and $\alpha$-catenin, thereby excluding $\beta$-catenin, provides strong intercellular adhesion but blocks cell rearrangment (Nagafuchi et al. 1994). Some observations suggest the possiblity that tyrosine phosphorylation of $\beta$-catenin, mediated by the src oncogene or the epidermal growth factor (EGF) receptor (for review, see Hülsken et al. 1994), might release E-cadherin from the otherwise metabolically stable complex. Subsequently, released E-cadherin might be endocytosed and replaced by newly synthesized E-cadherin in order to establish a new adhesive contact. The rapid disruption and reformation of adherens junction is clearly instrumental to facilitate a variety of morphogenetic movements that require some kind of intercellular motility /Gumbiner 1992).

In conclusion, our analysis of shg/DE-cadherin suggests that this molecule is the major epithelial cadherin in the Drosophila embryo. The function of the DE-cadherin-catenin complex in Drosophila appears to be very similar to the vertebrate complex. It is required for the formation and maintanence of the epithelial cell structure; the dynamic regulation of the complex is instrumental in allowing various morphogenetic movements that involve cell rearrangement to occur. The further analysis of the cadherin-catenin complex in Drosophila will be of general significance for our understanding of embryonic morphogenesis.

\section{Materials and methods}

\section{Genetics}

Three shg alleles where provided by C. Nüsslein-Volhard (Max Planck Institüt für Entwicklungsbiologie, Tübingen, Germany) (shg ${ }^{I H} ; s h g^{I G}$; shg $\left.{ }^{I S}\right\rangle$ and two alleles by Janis O'Donnell (shg ${ }^{E 17 B}$; shg ${ }^{S H N-1}$; O'Donnell et al. 1989). We generated five alleles (including $s h g^{\mathrm{g} 317}$ and $s h g^{\mathrm{g} 119}$ ) in a $\gamma$-ray mutagenesis experiment and 12 alleles (including $s g^{\mathrm{I}}{ }^{\mathrm{B} 2}$ ) in an $\mathrm{x}$-ray $\mathrm{mu}$ - 
tagenesis experiment. For both screens $c n b w$ males were irradiated with 5000 rads and shg mutations were recovered with standard $\mathrm{F}_{2}$-screen protocols. The $\mathrm{P}$ element-induced allele shg ${ }^{\mathrm{P} 34-1}$ was isolated from 1861 lines that carry the PlacW (Bier et al. 1989) insertions on the second chromosome (Török et al. 1993) by crossing these lines against the shg deficiency Df(2R)D17 (O'Donnell et al. 1989). Thirty-six lines were recovered as lethals over $D f(2 R) D 17$ and tested further for complementation of the $\operatorname{shg} g^{\mathrm{g} 317}$ point mutations.

To excise the PlacW element from the shg locus, $s h g^{\mathrm{P} 34-1}$ was combined with the $\Delta 2-399 \mathrm{~B}$ source of $\mathrm{P}$ transposase (Robertson et al. 1988). Of 186 independent excision events isolated, 83 lines were homozygous viable. All shg alleles were examined by cuticle preparation (Wieschaus and Nüsslein-Volhard 1986).

Flies that carry the $N_{\text {intra }}$ insertion on the third chromosome (Struhl et al. 1993) and $N_{\text {intra }}$ shgg ${ }^{g 17}$ or $N_{\text {intra }}$ shg ${ }^{\text {I2B2 }}$ double mutants were heat-shocked at $37^{\circ} \mathrm{C}$ between 3.5 and $6.5 \mathrm{hr}$ of development. As $c t$ mutation, we used the null allele $c t^{C 145}$ (Lindsley and Zimm 1992).

\section{Molecular biology}

A $10-\mathrm{kb}$ genomic fragment flanking the P34-1 insertion was isolated through plasmid rescue from EcoRI-digested genomic DNA prepared from $\mathrm{shg}^{\text {P34-1 }}$ flies (Pirrotta 1986; Bier et al. 1989). Subsequently, several genomic phages were isolated from a Drosophila EMBL3 library (kindly provided by Dr. J. Tamkun, University of California, Santa Cruz) using standard procedures (Sambrook et al. 1989). A total of $\sim 20 \mathrm{~kb}$ of genomic DNA was isolated that contain the shg locus (Fig. 1A). To determine the extent of the $s h g$ transcription unit, oligonucleotide probes that recognize the 5' (CGTTGTGAACTTGTACTTTCTGGCGA) and 3' (TTGTCCCGACACTATCAACATCCGTA) end of the full-length $D E$-cadherin cDNA (Oda et al. 1994) were hybridized with the cloned genomic DNA. Oligonucleotides were labeled with the DIG Oligonucleotide Tailing Kit (Boehringer Mannheim). Labeling and hybridization were according to manufacturer's instructions. The position of the P34-1 insertion was determined by sequencing the termini of the plasmid rescue fragment. The location of the shg locus was determined by hybridizing digoxigenin-labeled DNA of the white gene to the chromosome carrying the P34-1 insertion and digoxigenin-labeled phages clones to Oregon- $R$ chromosomes (Pardue 1986). In situ hybridizations of whole-mount embryos were done as described (Tautz and Pfeifle 1989) using the digoxigenin-labeled plasmid rescue fragment as probe. Digoxigenin-labeled DNA probes were generated with random priming (Genius Kit, Boehringer Mannheim). PCR reactions to characterize wild-type revertants contained 200-400 ng of genomic DNA and $250 \mathrm{ng}$ of each of three primers: a primer that recognizes both ends of the $P$ element (ACCACCTTATGTTATTTCATCATG) and two primers flanking the P34-l insertion site to the left (CGCCAGAAAGTACAAGTTCACAAC) and the right (GCTTCTGGACATTCGGCTGGACACT), respectively. DNA was amplified in 30 circles at $95^{\circ} \mathrm{C}(1 \mathrm{~min}), 55^{\circ} \mathrm{C}(1 \mathrm{~min})$, and $72^{\circ} \mathrm{C}(1 \mathrm{~min})$.

\section{Germ-line clones}

Females that carry a shg mutation over the $O V O^{D I}-F R T-2 R$ chromosome (Chou and Perrimon 1992) were irradiated during the first and early second larval instar with 1200-rad x-ray to induce mitotic crossover in the germ line. These females were crossed against males carrying the same shg allele over the balancer SM6b (Lindsley and Zimm 1992). In VVO $^{D 1}$ females, normal oogenesis is blocked; only oogonia in that mitotic recombination on the right arm of the second chromosome /and that are thus homozygous for shg) can develop. In the wild-type control, 477 fertilized eggs (from 400 females) were recovered that developed normally. However, control females laid a number of highly deformed eggs that did not develop and that we attribute to the leakiness of the $O V O^{D 1}-F R T-2 R$ chromosome. Therefore, we only examined developing eggs in this experiment. Using the alleles $s h g^{g 317}$ (200 females) and $\operatorname{shg}^{I H}$ (250 females) no developing eggs were recovered. For the alleles shgg119 $1400 \mathrm{fe}-$ males) and $s g^{P 34-1}$ (500 females) a total of 74 developing eggs were recovered. About $20-25$ eggs that showed a similar distribution of phenotypes were recovered from each of three independent experiments. From a total of 74 embryos, 24 developed normally into adult flies, 14 embryos showed a weak shg mutant cuticle phenotype, 30 embryos had strong cuticle defects comparable with class III and IV alleles (Fig. 3G), and 6 embryos exhibited defects that were substantially stronger than those caused by class IV alleles (Fig. $3 \mathrm{H}$ ). We assume that the embryos that developed normally and that showed a weak mutant phenotype received a paternal wild-type copy of $s h g$, whereas the remaining embryos were homozygous mutant.

\section{Immunohistochemistry and electron microscopy}

The following antibodies were used in this study: Anti-Fas III antibody MAb 2D5 (Patel et al. 1987), MAb 22C10 (kindly provided by Dr. S. Benzer, California Institute of Technology, Pasadena), anti-Crb antibody MAb Cq4 (Tepass and Knust 1993), anti-Arm antibody MAb N2-7A1 (kindly provided by Dr. M. Peifer, University of North Carolina, Chapel Hill), and anti-D $\alpha$ catenin antibody MAb DCAT-1 (Oda et al. 1993). The expression of the lacZ markers from the sevenup PlacZ line H162 (Mlodzik et al. 1990) and the PlacZ94 line (kindly provided by Dr. J.A. Campos-Ortega, Universität zu Köln, Germany) was detected with a polyclonal anti- $\beta$-galactosidase antibody (Cappel). Antibody stainings, preparations for electron microscopy, and sectioning were done as described (Tepass and Knust 1993; Tepass and Hartenstein 1994a). Embryos stained with the $D \alpha$ catenin and Arm antibodies were fixed with heat (Miller et al. 1989). This treatment greatly emphasizes the signal at adherens junctions.

\section{Acknowledgments}

We thank Drs. C. Nüsslein-Volhard, J. O'Donnell, J. Lengyel, G. Struhl, and the Bloomington Stock Center for providing fly stocks and Drs. T. Uemura, M. Takeichi, S. Benzer, C. Goodman, M. Peifer, M. Mlodzik, and J. Campos-Ortega for providing antibodies and PlacZ markers. We are grateful for the open exchange of unpublished data with Drs. T. Uemura and M. Takeichi. We appreciate critical reading of the manuscript by Dr. D. Godt. U.T. was a fellow of the Human Frontier Science Fellowship Organization (HFSPO) and the Jonsson Cancer Center Foundation (JCCC). E.G. was supported by a U.S. Public Health Service National Research Service Award. This work was supported by a National Institutes of Health grant (NS29367) to V.H.

\section{References}

Bier, E., H. Vaessin, S. Shepherd, K. Lee, K. McCall, S. Barbel, L. Ackerman, R. Carretto, T. Uemura, E. Grell, L.Y. Jan, and Y.N. Jan. 1989. Searching for pattern and mutation in the Drosophila genome with a P-lacZ vector. Genes \& Dev. 3: 1273-1287.

Birchmeier, W. 1995. E-cadherin as a tumor (invasion) suppres- 
sor gene. BioEssays 17: 97-99.

Brieher, W.M. and B.M. Gumbiner. 1994. Regulation of C-cadherin function during activin induced morphogenesis of $\mathrm{Xe}$ nopus animal caps. J. Cell. Biol. 126: 519-527.

Campos-Ortega, J.A. 1993. Early neurogenesis in Drosophila melanogaster. In The development of Drosophila melanogaster (ed. M. Bate and A. Martinez-Arias), pp. 1091-1130. Cold Spring Harbor Laboratory Press, Cold Spring Harbor, NY.

Clark, H.F., D. Brentrup, K. Schneitz, A. Bieber, C. Goodman, and M. Noll. 1995. Dachsous encodes a member of the cadherin superfamily that controls imaginal disc morphogenesis in Drosophila. Genes \& Dev. 9: 1530-1542.

Condic, M.L., D. Fristrom, and J.W. Fristrom. 1991. Apical cell shape changes during Drosophila imaginal leg disc elongation: a novel morphogenetic mechanism. Development 111: 23-33.

Costa, M., D. Sweeton, and E. Wieschaus. 1993. Gastrulation in Drosophila: Cellular mechansms of morphogenetic movements. In The Development of Drosophila melanogaster /ed. M. Bate and A. Martinez-Arias), pp. 425-466. Cold Spring Harbor Laboratory Press, Cold Spring Harbor, NY.

Chou, T.B. and N. Perrimon. 1992. Use of a yeast site-specific recombinase to produce female germline chimeras in Drosophila. Genetics 131: 643-653.

Detrick, R.J., D. Dickey, and C.R. Kintner. 1990. The effects of $\mathrm{N}$-cadherin misexpression on morphogenesis in Xenopus embryos. Neuron 4: 493-506.

Doe, C.Q. 1992. Molecular markers for identified neuroblasts and ganglion mother cells in the Drosophila nervous system. Development 116: 855-863.

Foe, V.E., G.M. Odell, and B.A. Edgar. 1993. Mitosis and morphogenesis in the Drosophila embryo. In The Development of Drosophila melanogaster (ed. M. Bate and A. MartinezArias), pp. 1091-1130. Cold Spring Harbor Laboratory Press, Cold Spring Harbor, NY.

Fujimori, T., M. Miyatani, and M. Takeichi. 1990. Ectopic expression of $\mathrm{N}$-cadherin perturbs histogenesis in Drosophila embryos. Development 110: 97-104.

Gabbert, H., R. Wagner, R. Moll, and C.D. Gerharz. 1985. Tumor dedifferentiation: An important step in tumor invasion. Exp. Metastasis 3: 257-279.

Geiger, B. and O. Ayalon. 1992. Cadherins. Ann. Rev. Cell Biol. 8: $307-332$.

Gumbiner, B.M. 1992. Epithelial morphogenesis. Cell 69: 385387.

Hartenstein, V. and J.A. Campos-Ortega. 1984. Early neurogenesis in wildtype Drosophila melanogaster. Roux's Arch. Dev. Biol. 193: 308-325.

Hartenstein, V., U. Tepass, and E. Gruszynski-de Feo. 1994a. The development of the Drosophila stomatogastric nervous system. I. Comp. Neur. 350: 367-381.

Hartenstein, V., A. Younossi-Hartenstein, and A. Lekven. 1994b. Delamination and division in the Drosophila neurectoderm: Spatio-temporal pattern, cytoskeletal dynamics, and common control by neurogenic and segment polarity genes. Dev. Biol. 165: 480-499.

Hülsken, J., J. Behrens, and W. Birchmeier. 1994. Tumor-suppressor gene products in cell contacts: The cadherin-APCarmadillo connection. Curr. Opin. Cell Biol. 6: 711-716.

Kemler, R. 1993. From cadherins to catenins: Cytoplasmic protein interactions and regulation of cell adhesion. Trends Genet. 9: 317-321.

Kintner, C. 1992. Regulation of embryonic cell adhesion by the cadherin cytoplasmic domain. Cell 69: 225-236.

Levine, E., C.H. Lee, C. Kintner, and B.M. Gumbiner. 1994.
Selective disruption of E-cadherin function in early Xenopus embryos by a dominant negative mutant. Development 120: 901-909.

Lieber, T., S. Kidd, E. Alcamo, V. Corbin, and M.W. Young. 1993. Antineurogenic phenotypes induced by truncated Notch proteins indicate a role in signal transduction and may point to a novel function for Notch in nuclei. Genes \& Dev. 7: 1949-1965.

Lindsley, D.L. and G.G. Zimm. 1992. The genome of Drosophila melanogaster. Academic Press, San Diego, CA.

Liu, S. and J. Jack. 1992. Regulatory interactions and role in cell type specification of the Malpighian tubules by cut, Krüppel and caudal genes of Drosophila. Dev. Biol. 150: 133-143.

Mahoney, P.A., U. Weber, P. Onofrechuk, H. Biessmann, P.J. Bryant, and C.S. Goodman. 1991. The fat tumor suppressor gene in Drosophila encodes a novel member of the cadherin gene superfamily. Cell 67: 853-868.

McNeill, H., M. Ozawa, R. Kemler, and W.J. Nelson. 1990. Novel function of the cell adhesion molecule uvomorulin as an inducer of cell surface polarity. Cell 62: 309-316.

Miller, K.G., C.M. Field, and B.M. Alberts. 1989. Actin-binding proteins from Drosophila embryos: A complex network of interacting proteins detected by F-actin affinity chromatography. J. Cell Biol. 109: 2963-2975.

Mlodzik, M., Y. Hiromi, U. Weber, C.S. Goodman, and G. Rubin. 1990. The Drosophila seven-up gene, a member of the steroid receptor gene superfamily, controls photoreceptor cell fates. Cell 60: 211-224.

Nagafuchi, A., S. Ishihara, and S. Tsukiata. 1994. The roles of catenins in the cadherin-mediated cell adhesion: Functional analysis of E-cadherin - $\alpha$-catenin fusion molecules. I. Cell Biol. 127: 235-245.

Nüsslein-Volhard, C., E. Wieschaus, and H. Kluding. 1984. Mutations affecting the pattern of the larval cuticle in Drosophila melanogaster. I. Zygotic loci on the second chromosome. Roux's Arch. Dev. Biol. 193: 267-282.

Oda, H., T. Uemura, T. Shiomi, A. Nagafuchi, S. Tsukita, and M. Takeichi. 1993. Identification of a Drosophila homologue of $\alpha$-catenin and its association with the armadillo protein. I. Cell Biol. 121: 1133-1140.

Oda, H., T. Uemura, Y. Harada, Y. Iwai, and M. Takeichi. 1994. A Drosophila homolog of cadherin associated with Armadillo and essential for embryonic cell-cell adhesion. Dev. Biol. 165: 716-726.

O'Donnell, J., R. Boswell, T. Reynolds, and W. Mackay. 1989. A cytogenetic analysis of the Punch-tudor region of Chromosome 2R in Drosophila melanogaster. Genetics 121: 273280.

Pardue, M.L. 1986. In situ hybridization to DNA of chromosomes and nuclei. In Drosophila, a practical approach fed. D.R. Roberts), pp. 111-137. IRL Press, Oxford, Washington D.C.

Patel, N.H., P.M. Snow, and C.S. Goodman. 1987. Characterization and cloning of fasciclin III: A glycoprotein expressed on a subset of neurons and axon pathways in Drosophila. Cell 48: 975-988.

Peifer, M. 1993. The product of the Drosophila segment polarity gene armadillo is part of a protein complex resembling the vertebrate adherens junction. J. Cell Sci. 105: 993-1000.

. 1995. Cell adhesion and signal transduction: The Armadillo connection. Trends Cell Biol. 5: 224-229.

Peifer, M., S. Orsulic, D. Sweeton, and E. Wieschaus. 1993. A role for the Drosophila segment polarity gene armadillo in cell adhesion and cytoskeletal integrity during oogenesis. Development 118: 681-691.

Pirrotta, V. 1986. Cloning Drosophila genes. In Drosophila, a 
practical approach (ed. D.R. Roberts), pp. 83-110. IRL Press, Oxford/Washington D.C.

Ranscht, B. 1994. Cadherins and catenins: Interactions and functions in embryonic development. Curr. Opin. Biol. 6: $740-746$.

Rebay, I., R.G. Fehon, and S. Artavanis-Tsakonas. 1993. Specific truncations of Drosophila Notch define dominant activated and dominant-negative forms of the receptor. Cell 74: 319330 .

Riggleman, B., P. Schedl, and E. Wieschaus. 1990. Spacial expression of the Drosophila segment polarity gene armadillo is posttranscriptionally regulated by wingless. Cell 63: 549560.

Robertson, H.M., C.R. Preston, R.W. Phillis, D. JohnsonSchlitz, W.K. Benz, and W.R. Engels. 1988. A stable genomic source of P-element transposase in Drosophila melanogaster. Genetics 118: 461-470.

Rodriguez-Boulan, E. and W.J. Nelson. 1989. Morphogenesis of the polarized epithelial cell phenotype. Science 245: 718725.

Sambrook, J., E.F. Fritsch, and T. Maniatis. 1989. Molecular cloning: A laboratory manual Cold Spring Harbor Press, Cold Spring Harbor, NY.

Skaer, H. 1993. The alimentary canal. In The development of Drosophila melanogaster led. M. Bate and A. MartinezArias), pp. 941-1012. Cold Spring Habor Laboratory Press, Cold Spring Harbor, NY.

Struhl, G., K. Fitzgerald, and I. Greenwald. 1993. Intrinsic activity of the Lin-12 and Notch intracellular domains in vivo. Cell 74: 331-345.

Takeichi, M. 1988. The cadherins: Cell-cell adhesion molecules controling animal morphogenesis. Development 102: 639-655.

. 1991. Cadherin cell adhesion receptors as a morphogenetic regulator. Science 251: 1451-1455.

- 1995. Morphogenetic roles of classic cadherins. Curr. Opin. Cell Biol. 7: 619-627.

Tautz, D. and C. Pfeifle. 1989. A non-radioactive in situ hybridization method for the localization of specific RNAs in Drosophila embryos reveals a translational control of the segmentation gene hunchback. Chromosoma 98: 81-85.

Tepass, U., C. Theres, and E. Knust. 1990. crumbs encodes an EGF-like protein expressed on apical membranes of Drosophila epithelial cells and required for organization of epithelia. Cell 61: 787-799.

Tepass, U., and V. Hartenstein. 1994a. The development of intercellular junctions in the Drosophila embryo. Dev. Biol. 161: $563-596$.

- 1994b. The formation of the midgut epithelium in Drosophila depends on the interaction of endoderm and mesoderm. Development 120: 579-590.

1995. Neurogenic and proneural genes control the specification of non-neuronal cell types in the Drosophila endoderm. Development 121: 393-405.

Tepass, U. and E. Knust. 1990. Phenotypic and developmental analysis of mutations at the crumbs locus, a gene required for the development of epithelia in Drosophila melanogaster. Wilhelm Roux's Arch. Dev. Biol. 199: 189-206.

- 1993. crumbs and stardust act in a genetic pathway that controls the organization of epithelia in Drosophila melanogaster. Dev. Biol. 158: 311-326.

Török, T., G. Tick, M. Alvarado, and I. Kiss. 1993. P lac-W insertional mutagenesis on the second chromosome of Drosophila melanogaster: Isolation of lethals with different overgrowth phenotypes. Genetics 135: 71-80.
Uemura, T., H. Oda, R. Kraut, S. Hayashi, S. Kataoka, and M. Takeichi. 1996. Zygotic DE-cadherin expression is required for processes of dynamic epithelial cell rearrangement in the Drosophila embryo. Genes \& Dev. (this issue).

White, K., M.E. Grether, J.M. Abrams, L. Young, K. Farrell, and H. Steller. 1994. Genetic control of programmed cell death in Drosophila. Science 264: 677-683.

Wieschaus, E. and J. Nüsslein-Volhard. 1986. Looking at embryos. In Drosophila, a practical approach (ed. D.R. Roberts), pp. 199-228. IRL Press, Oxford/Washington D.C.

Wodarz, A., U. Hinz, M. Engelbert, and E. Knust. 1995. Expression of Crumbs confers apical character on plasma membrane domains of ectodermal epithelia of Drosophila. Cell 82: $67-76$. 


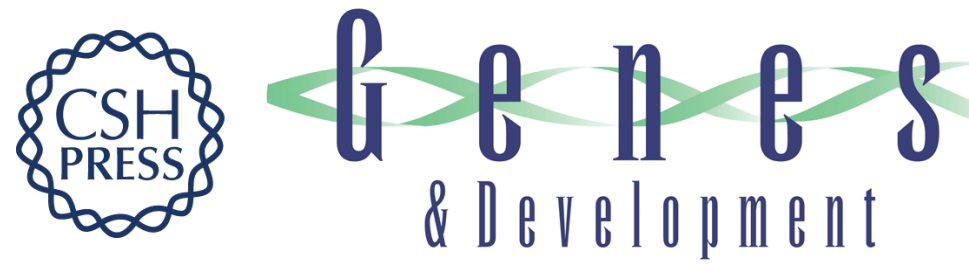

\section{shotgun encodes Drosophila E-cadherin and is preferentially required during cell rearrangement in the neurectoderm and other morphogenetically active epithelia.}

U Tepass, E Gruszynski-DeFeo, T A Haag, et al.

Genes Dev. 1996, 10:

Access the most recent version at doi:10.1101/gad.10.6.672

References This article cites 52 articles, 22 of which can be accessed free at: http://genesdev.cshlp.org/content/10/6/672.full.html\#ref-list-1

License

Email Alerting Receive free email alerts when new articles cite this article - sign up in the box at the top Service right corner of the article or click here.

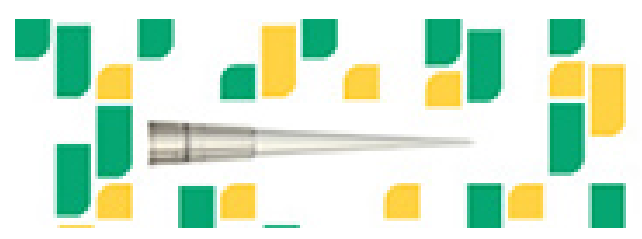

Focused on your science. 